\title{
Retraction Note to: Why money meanings matter in decisions to donate time and money
}

\author{
Promothesh Chatterjee $^{1} \cdot$ Randall L. Rose ${ }^{2}$. \\ Jayati $\operatorname{Sinha}^{3}$
}

Published online: 5 March 2016

(C) Springer Science+Business Media New York 2016

\section{Retraction Note to: Mark Lett (2013) 24(2):109-118 DOI 10.1007/s11002-012-9215-0}

This article has been retracted at the suggestion of journal Editors-in-Chief, Peter N. Golder and Joel H. Steckel. The article's authors unanimously requested retraction of Study 3 based on unexplained anomalies in the data and coding errors. As a result, the editors deem it appropriate to retract the entire article.

The online version of the original article can be found at http://dx.doi.org/10.1007/s11002-012-9215-0.

\author{
Jayati Sinha \\ jsinha@email.arizona.edu \\ Promothesh Chatterjee \\ chatterjee@ku.edu \\ Randall L. Rose \\ roser@moore.sc.edu
}

1 School of Business, University of Kansas, 1300 Sunnyside Avenue, Lawrence, KS 66045-7585, USA

2 Darla Moore School of Business, University of South Carolina, 1705 College Street, Columbia, SC 29208, USA

3 Eller College of Management, University of Arizona, McClelland Hall 320 Y, Tucson, AZ 85721-0108, USA 